\title{
KARAKTERISTIK MANAJEMEN PENDIDIKAN BERBASIS SEKOLAH
}

\author{
H. M. Jufri Dolong \\ Dosen DPK UIN Syarief Hidayatullah Jakarta \\ Email: jufridolong@yahoo.co.id
}

\begin{abstract}
M B S$ is intended to increase school autonomy, determine what it needs to be taught, and manage the resources available to innovate. MBS also has great potential to create professional principals, teachers and administrators. Thus, schools will be responsive to the needs of each student and school community. Student achievement can be optimized through the direct participation of parents and community. MBS is one of the answers to the provision of regional autonomy in the field of education and has been invited in Law Number 20 Year 2003 regarding Sisdiknas Article 51 Paragraph (1) which reads, "Management of early childhood education units, primary education and secondary education implemented based on minimum service standards with the principle of school-based management.
\end{abstract}

Keywords: Characteristics, Education Management and School

\section{PENDAHULUAN}

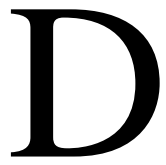
alam UU RI NO. 22 Tahun 1999 tentang Pemerintahan Daerah disebutkan bahwa wujud otonomi daerah (otda) dalam pelaksanaannya adalah otonomi luas, nyata dan bertanggung jawab. Otonomi yang luas artinya mencakup kewenangan semua bidang kecuali hankam, peradilan, moneter dan fiscal, agama, politik luar negeri, dan kewenangan lainnya. Otonomi yang nyata artinya keleluasan daerah untuk menyelenggarakan kewenangan pemerintah di bidang tertentu yang nyata ada dan diperlukan serta tumbuh dan berkembang di daerah. Otonomi yang bertanggung jawab artinya pertanggungjawaban daerah sebagai konsekuensi pemberian hak dan kewenangan kepada daerah dalam wujud tugas dan kewajiban daerah.

Manajemen sekolah selama Orde Baru yang sangat sentralistik telah menempatkan sekolah pada posisi marginal, kurang diberdayakan tetapi malah diperdayakan, kurang mandiri, pasif atau menunggu instruksi, bahkan inisiatif dan kreativitasnya untuk berkembang terpasung. Akan tetapi, dengan diberlakukannya otonomi daerah sejak 1 Januari 2001, Depdiknas terdorong untuk melakukan reorientasi manajemen sekolah dari manajemen pendidikan berbasis pusat menjadi Manajemen Berbasis Sekolah/MBS (School Based Management/SBM) atau disebut juga sebagai site based management yang diterapkan menjadi MBS.

Syamsuddin (1999) menjelaskan bahwa MBS merupakan salah satu alternative pengelolaan sekolah dalam kerangka desentralisasi dalam bidang pendidikan yang memungkinkan adanya otonomi yang luas di tingkat sekolah, partisipasi masyarakat 
yang tinggi agar sekolah lebih leluasa dalam mengelola sumber daya dan mengalokasikannya sesuai dengan prioritas, kebutuhan dan potensi setempat. ${ }^{1} \mathrm{MBS}$ adalah bentuk alternative sekolah sebagai hasil dari desentralisasi pendidikan. MBS pada prinsipnya bertumpu pada sekolah dan masyarakat serta jauh dari birokrasi yang sentralistik. MBS berpotensi untuk meningkatkan partisipasi masyarakat, pemerataan, afisiensi, serta manajemen yang bertumpu pada tingkat sekolah.

MBS dimaksudkan meningkatkan otonomi sekolah, menentukan sendiri apa yang perlu diajarkan, dan mengelola sumber daya yang ada untuk berinovasi. MBS juga memiliki potensi yang besar untuk menciptakan kepala sekolah, guru dan administrator yang professional. Dengan demikian, sekolah akan bersifat responsive terhadap kebutuhan masing-masing siswa dan masyarakat sekolah. Prestasi belajar siswa dapat dioptimalkan melalui partisipasi langsung orangtua dan masyarakat. ${ }^{2}$ Oleh karena itu, MBS wajib diketahui, dihayati, dan diamalkan oleh warga negara Indonesia terutama mereka yang berkecimpung di dunia pendidikan anak usia dini, pendidikan dasar, dan pendidikan menengah. ${ }^{3}$

Berdasarkan uraian di atas, dapat disimpulkan bahwa sekolah yang menerapkan MBS mengisyaratkan adanya proses pelaksanaan pendidikan yang efektif dengan adanya pelibatan atau partisipasi dari banyak pihak yang termasuk dalam golongan tenaga kependidikan. Oleh karena itu, dalam penerapan MBS tersebut, ada beberapa karakteristik Manajemen Berbasis Sekolah yang perlu diperhatikan agar pelaksanaannya berjalan dengan baik.

\section{PEMBAHASAN}

\section{A. Karakteristik Manajemen Berbasis Sekolah}

MBS wajib diketahui, dihayati, dan diamalkan oleh warga negara Indonesia terutama mereka yang berkecimpung di dunia pendidikan anak usia dini, pendidikan dasar, dan pendidikan menengah. Oleh karena itu, ada beberapa karakteristik yang dimiliki MBS yang wajib dipahami oleh sekolah yang ingin menerapkannya. Diharapkan sekolah yang memperhatikan dan memiliki karakteristik MBS mampu menerapkan MBS dengan sukses. Dalam bukunya Manajemen Berbasis Sekolah, Nurkolis menguraikan bahwa ada delapan karakteristik Manajemen Berbasis Sekolah, diantaranya ${ }^{4}$ :

\footnotetext{
${ }^{1}$ Engkoswara dan Aan Komariah, Administrasi Pendidikan, (Cet. II; Bandung: Alfabeta, 2011), h. 293.

${ }^{2}$ Fasli Jalal dan Dedi Supriadi, Reformasi Pendidikan dalam Konteks Otonomi Daerah, (Yogyakarta: Adicita Karya Nusa, 2001), h. 160.

${ }^{3}$ Husaini Usman, Manajemen: Teori Praktik dan Riset Pendidikan, (Edisi Kedua; Jakarta: Bumi Aksara, 2008), h. 573.

${ }^{4}$ Nurkolis, Manajemen Berbasis Sekolah: Teori, Model dan Aplikasi, (Jakarta: PT Grasindo, 2003), h. 56.
} 
1. Sekolah dengan MBS memiliki misi atau cita-cita menjalankan sekolah untuk mewakili sekelompok harapan bersama, keyakinan dan nilai-nilai sekolah, membimbing warga sekolah di dalam aktivitas pendidikan dan memberi arah kerja. Misi ini mempunyai pengaruh yang besar terhadap fungsi dan efektivitas sekolah, karena dengan misi ini warga sekolah dapat mengembangkan budaya organisasi sekolah yang tepat, membangun komitmen yang tinggi terhadap sekolah, dan mempunyai insiatif untuk memberikan tingkat layanan pendidikan yang lebih baik.

2. Aktivitas pendidikan dijalankan berdasarkan karakteristik kebutuhan dan situasi sekolah. Hakikat aktivitas sangat penting bagi sekolah untuk meningkatkan kualitas pendidikan, karena secara tidak langsung memperkenalkan perubahan manajemen sekolah dari menajemen kontrol eksternal menjadi model berbasis sekolah.

3. Terjadinya proses perubahan strategi manajemen yang menyangkut hakikat manusia, organisasi sekolah, gaya pengambilan keputusan, gaya kepemim-pinan, penggunaan kekuasaan, dan keterampilan-keterampilan manajemen. Oleh karena itu dalam konteks pelaksanaan MBS, perubahan strategi manajemen lebih memandang pada apek pengembangan yang tepat dan relevan dengan kebutuhan sekolah.

4. Keleluasaan dan keweangan dalam pengelolaan sumber daya yang efektif untuk mencapai tujuan pen-didikan, guna memecahkan masalah-masalah pendidikan yang dihadapi, baik tenaga kependidikan, keuangan dan sebagainya.

5. MBS menuntut peran aktif sekolah, adiministrator sekolah, guru, orang tua, dan pihak-pihak yang terkait dengan pendidikan di sekolah. Dengan MBS sekolah dapat me-ngembangkan siswa dan guru sesuai dengan karakteristik sekolah masingmasing. Dalam konteks ini, sekolah berperan mengembangkan insiatif, memecahkan masalah, dan mengeksplorasi semua kemungkinan untuk memfasilitasi efektivitas pembelajaran. Demikian halnya dengan unsur-unsur lain seperti guru, orang tua, komite sekolah, administrator sekolah, dinas pendidikan, dan sebagainya sesuai dengan perannya masing-masing.

6. MBS menekankan hubungan antar manusia yang cenderung terbuka, bekerja sama, semangat tim, dan komitmen yang saling menguntungkan. Oleh karena itu, iklmi orgnanisasi cenderung mengarah ke tipe komitmen sehingga efektivitas sekolah dapat tercapai.

7. Peran administrator sangat penting dalam kerangka MBS, termasuk di dalamnya kualitas yang dimiliki administrator.

8. Dalam MBS, efektivitas sekolah dinilai menurut indikator multitingkat dan multisegi. Penilaian tentang efektivitas sekolah harus mencakup proses pembelajaran dan metode untuk membantu kemajuan sekolah. Oleh karena itu, penilaian efektivitas sekolah hatus memperhatikan multitingkat, yaitu pada tingkat sekolah, kelompok, dan individu, serta indikator multisegi yaitu input, proses dan output sekolah serta perkembangan akademik siswa. 


\section{B. Indikator Keberhasilan Pelaksanaan MBS}

Menurut Depdiknas, karakteristik yang harus dimiliki oleh sekolah sebagai indicator pelaksanaan MBS yang berhasil adalah sebagai berikut ${ }^{5}$ :

\section{Input Pendidikan}

a. Memiliki kebijakan mutu

Secara formal, sekolah menyatakan dengan jelas tentang keseluruhan kebijakan, tujuan, dan sasaran sekolah yang berkaitan dengan mutu. Kebijakan, tujuan, dan sasaran mutu tersebut dinyatakan oleh kepala sekolah dan disosialisasikan kepada semua warga sekolah sehingga tertanam pemikiran, tindakan, kebiasaan, hingga sampai pada kepemilikan karakter mutu oleh warga sekolah.

b. Sumber daya tersedia dan siap

Sumberdaya merupakan input penting yang diperlukan untuk kelangsungan proses pendidikan di sekolah. Tanpa sumberdaya yang memadai, proses pendidikan di sekolah tidak akan berlangsung secara memadai dan pada akhirnya sasaran sekolah tidak akan tercapai. Sumberdaya dapat dikelompokkan menjadi dua, yaitu sumberdaya manusia dan sumberdaya selebihnya (uang, peralatan, perlengkapan, bahan, dan sebagainya) dengan penegasan bahwa sumberdaya selebihnya tidak mempunyai arti apapun bagi perwujudan sasaran sekolah tanpa campur tangan sumber daya manusia. Secara umum, sekolah yang menerapkan MBS harus memiliki tingkat kesiapan sumberdaya yang memadai untuk menjalankan proses pendidikan. Artinya, segala sumberdaya yang diperlukan untuk menjalankan proses pendidikan harus tersedia dan dalam keadaan siap. Ini bukan berarti bahwa sumberdaya yang ada harus mahal, tetapi sekolah yang bersangkutan dapat memanfaatkan keberadaan sumberdaya yang ada dilingkungan sekolahnya. Oleh karena itu, diperlukan kepala sekolah yang mampu memobilisasi sumberdaya yang ada disekitarnya.

c. Memiliki harapan dan prestasi yang tinggi

Sekolah yang menerapkan MBS mempunyai dorongan dan harapan yang tinggi untuk meningkatkan prestasi peserta didik dan sekolahnya. Kepala sekolah memiliki komitmen dan motivasi yang kuat untuk meningkatkan mutu sekolah secara optimal. Guru memiliki komitmen dan harapan yang tinggi bahwa anak didiknya dapat mencapai tingkat prestasi yang maksimal, walaupun dengan segala keterbatasan sumberdaya pendidikan yang ada di sekolah. Peserta didik juga mempunyai motivasi untuk selalu meningkatkan diri untuk berprestasi sesuai dengan bakat dan kemampuannya. Harapan terbesar dari ketiga unsur sekolah ini merupakan salah satu faktor yang menyebabkan sekolah selalu dinamis untuk menjadi lebih baik dari keadaan sebelumnya.

${ }^{5}$ Nur Aedi, Dasar-Dasar Manajemen Pendidikan, (Cet. II; Yogyakarta: Gosyen Publishing, 2015), h. 173. 


\section{Proses}

a. Efektifitas proses belajar mengajar tinggi

Sekolah yang menerapkan MBS memiliki efektivitas proses belajar mengajar (PBM) yang tinggi. Hal ini ditunjukkan oleh sifat PBM yang menekankan pada pemberdayaan peserta didik. PBM bukan sekedar memorisasi dan recall atau penekanan pada penguasaan pengetahuan tentang apa yang diajarkan (logos), tetapi lebih menekankan pada internalisasi tentang apa yang diajarkan sehingga tertanam dan berfungsi sebagai muatan nurani dan dihayati (ethos) serta dipraktikkan dalam kehidupan sehari-hari oleh peserta didik (pathos). Belajar yang efektif juga mengacu pada pilar-pilar pendidikan menurut UNESCO yaitu:

1) Learning to know yaitu belajar untuk mengetahui

2) Learning to do yaitu belajar untuk melakukan

3) Learning to live together yaitu belajar untuk bermasyarakat

4) Learning to be yaitu belajar tentang apa yang bisa dihubungkan dengan kehidupan sehari-hari, serta ditambah dengan

5) Learning to religi yaitu belajar untuk memahami agama.

Dengan demikian maka kegiatan pembelajaran akan dapat memiliki efektivitas yang tinggi.

b. Kepemimpinan sekolah kuat

Pada sekolah yang menerapkan MBS, kepala sekolah memiliki peran yang kuat dalam mengoordinasikan, menggerakkan, dan menyerasikan semua sumber daya pendidikan yang tersedia. Kepemimpinan kepala sekolah merupakan salah satu faktor yang dapat mendorong sekolah untuk dapat mewujudkan visi, misi, tujuan, dan sasaran sekolahnya melalui program-program yang dilaksanakan secara terencana dan bertahap.

Oleh karena itu, kepala sekolah dituntut memiliki kemampuan manajemen dan kepemimpinan yang tangguh agar mampu mengambil keputusan dan inisiatif prakarsa untuk meningkatkan mutu sekolah. Secara umum, kepala sekolah yang tangguh memiliki kemampuan memobilisasi sumberdaya sekolah, terutama sumberdaya manusia, untuk mencapai tujuan sekolah.

c. Pengelolaan yang efektif tenaga kependidikan

Sekolah dengan SBM memiliki pengelolaan tenaga kependidikan yang efektif. Tenaga kependidikan, terutama guru merupakan jiwa dari sekolah. Sekolah hanyalah merupakan wadah dan sekolah yang menerapkan MBS menyadari tentang hal ini. Oleh karena itu, pengelolaan tenaga kependidikan, mulai dari analisa kebutuhan, perencanaan, pengembangan, evaluasi kinerja, hubungan kerja, hingga imbal jasa merupakan garapan penting bagi seorang kepala sekolah.

Pada pengembangan tenaga kependidikan, hal tersebut harus dilaksanakan secara terus menerus mengingat kemajuan ilmu pengetahuan dan teknologi yang sedemikian pesat. Tenaga kependidikan yang diperlukan untuk menyukseskan MBS adalah tenaga 
kependidikan yang mempunyai komitmen tinggi dan selalu mampu dan sanggup menjalankan tugasnya dengan baik.

d. Sekolah memiliki budaya mutu

Sekolah MBS memiliki budaya mutu yang memiliki elemen-elemen sebagai berikut:(a) informasi kualitas harus digunakan untuk perbaikan, bukan untuk mengadili/mengontrol orang; (b) kewenangan harus sebatas pada tanggungjawab; (c) hasil harus diikuti penghargaan (rewards) atau sanksi (punishment); (d) kolaborasi dan sinergi, bukan kompetisi, harus menjadi basis untuk kerjasama; (e) warga sekolah merasa aman terhadap pekerjaannya; (f) atmosfir keadilan (fairness) harus ditanamkan; (g) imbal jasa harus sepadan dengan nilai pekerjaannya; dan (h) warga sekolah merasa memiliki sekolah.

e. Sekolah memiliki "teamwork" yang kompak, cerdas dan dinamis

Sekolah dengan MBS memiliki Team work. Team Work merupakan karakteristik yang dituntut oleh MBS, karena output pendidikan merupakan hasil kolektif warga sekolah, bukan hasil individual. Uraian dari team work itu sendiri adalah: $\mathrm{t}=$ together (bersama), $\mathrm{e}=$ empathy (peduli), $\mathrm{a}=$ assist (saling membantu), $\mathrm{m}=$ maturity, $\mathrm{w}=$ willingnes (sukarela), $\mathrm{o}=$ organisation (pengorganisasian), $\mathrm{r}=$ respect, $\mathrm{k}=$ kindness (ramah).

f. Sekolah memiliki kewenangan

Sekolah dengan MBS memiliki ewenangan sekolah yaitu melaksanakan yang terbaik bagi sekolahnya, sehingga dituntut untuk memiliki kemampuan dan kesanggupan kerja yang baik. Untuk menjadi mandiri sekolah harus memiliki sumber daya yang cukup untuk menjalankan tuganya.

g. Partisipasi warga sekolah dan masyarakat

Sekolah yang menerapkan MBS memiliki karakteristik bahwa partisipasi warga sekolah dan masyarakat merupakan bagian kehidupannya. Hal ini dilandasi oleh keyakinan bahwa makin tinggi tingkat partisipasi, makin besar rasa memiliki; makin besar pula rasa tanggung jawab, makin besar pula tingkat dedikasinya.

h. Sekolah memiliki keterbukaan (transparansi) manajemen

Keterbukaan/transparansi dalam pengelolaan sekolah merupakan karakteristik sekolah yang menerapkan MBS. Keterbukaan/transparansi ini ditunjukkan dalam pengambilan keputusan, perencanaan dan pelaksanaan kegiatan, penggunaan uang, dan sebagainya yang selalu melibatkan pihak-pihak terkait sebagai alat kontrol.

i. Sekolah memiliki kemauan untuk berubah (psikologi dan fisik)

Perubahan harus merupakan sesuatu yang menyenangkan bagi semua warga sekolah. Sebaliknya, kemapanan merupakan musuh sekolah. Tentu saja yang dimaksud dengan perubahan adalah peningkatan, baik bersifat fisik maupun psikologis. Artinya, 
setiap perubahan dilakukan, hasilnya diharapkan lebih baik dari sebelumnya (ada peningkatan) terutama mutu peserta didik.

j. Sekolah melakukan evaluasi dan perbaikan dan berkelanjutan

Sekolah dengan MBS selalu melakukan evaluasi dan perbaikan secara berkelanjutan. Evaluasi belajar secara teratur bukan hanya ditujukan untuk mengetahui tingkat daya serap dan kemampuan peserta didik, tetapi yang terpenting adalah bagaimana memanfaatkan hasil evaluasi belajar tersebut untuk memperbaiki dan menyempurnakan proses belajar mengajar di sekolah. Oleh karena itu, fungsi evaluasi menjadi sangat penting dalam rangka meningkatkan mutu peserta didik dan mutu sekolah secara keseluruhan dan terus menerus.

Perbaikan secara terus-menerus harus menjadi kebiasaan warga sekolah. Tiada hari tanpa perbaikan. Oleh karena itu, harus ada sistem mutu yang baku sebagai acuan bagi perbaikan. Sistem mutu yang dimaksud harus mencakup struktur organisasi, tanggung jawab, prosedur, proses, dan sumberdaya untuk menerapkan manajemen mutu.

k. Sekolah responsive dan antisipatif terhadap kebutuhan

Sekolah selalu tanggap/responsif terhadap berbagai aspirasi yang muncul bagi peningkatan mutu. Oleh karena itu, sekolah harus selalu dapat membaca lingkungan dan menanggapinya secara cepat dan tepat. Sekolah dituntut untuk tidak hanya mampu menyesuaikan diri terhadap perubahan/tuntutan, akan tetapi juga mampu mengantisipasi hal-hal yang mungkin akan terjadi. Menjemput bola adalah padanan kata yang tepat bagi istilah antisipatif.

1. Sekolah memiliki akuntabilitas

Akuntabilitas adalah bentuk pertanggungjawaban yang harus dilakukan sekolah terhadap keberhasilan program yang telah dilaksanakan. Akuntabilitas ini berbentuk laporan prestasi yang dicapai dan dilaporkan kepada pemerintah, orangtua siswa, dan masyarakat. Berdasarkan laporan hasil program tersebut, pemerintah dapat menilai apakah program MBS telah mencapai tujuan yang dikehendaki atau tidak.

Jika berhasil, pemerintah perlu memberikan penghargaan kepada sekolah yang bersangkutan sehingga dapat menjadi faktor pendorong untuk terus meningkatkan kinerjanya di masa yang akan datang. Akan tetapi, jika program tidak berhasil, pemerintah perlu memberikan teguran sebagai hukuman atas kinerjanya yang dianggap tidak memenuhi syarat. Demikian pula, para orangtua siswa dan anggota masyarakat dapat memberikan penilaian apakah program ini dapat meningkatkan prestasi anaknya secara individual dan kinerja sekolah secara keseluruhan.

Apabila hal ini berhasil dilakukan, orangtua peserta didik perlu memberikan semangat dan dorongan untuk peningkatan program yang akan datang. Akan tetapi, jika program tersebut kurang berhasil, orangtua siswa dan masyarakat berhak meminta pertanggungjawaban dan penjelasan sekolah atas kegagalan program MBS yang telah 
dilakukan. Dengan cara seperti ini, sekolah tidak akan main-main dalam melaksanakan program pada tahun-tahun yang akan datang.

m. Sekolah memiliki sustainabilitas

Sekolah yang efektif juga memiliki kemampuan untuk menjaga kelangsungan hidupnya (sustainabilitas), baik dalam program maupun pendanaannya. Sustainabilitas program dapat dilihat dari berkelanjutan program-program yang telah dirintis sebelumnya dan bahkan berkembang menjadi program-program baru yang belum pernah ada sebelumnya.

Sustainabilitas pendanaan dapat ditunjukkan oleh kemampuan sekolah dalam mempertahankan besarnya dana yang dimiliki dan bahkan makin besar jumlahnya. Sekolah memiliki kemampuan menggali sumberdana dari masyarakat, dan tidak sepenuhnya menggantungkan subsidi dari pemerintah bagi sekolah-sekolah negeri.

\section{n. Output}

Sekolah memiliki output yang diharapkan. Output sekolah adalah prestasi sekolah yang dihasilkan melalui proses pembelajaran dan manajemen di sekolah. Pada umumnya, output dapat diklasifikasikan menjadi dua, yaitu output berupa prestasi akademik (academic achievement) dan output yang berupa prestasi non akademik (nonacademic achievement). Output prestasi akademik misalnya, NUAN/NUNAS, lomba karya ilmiah remaja, lomba (Bahasa Inggris, Matematika, Fisika), cara berfikir (kritis, kreatif divergen, nalar, rasional, induktif, deduktif, dan ilmiah). Output nonakademik, misalnya akhlak/budi pekerti, dan perilaku sosial yang baik seperti bebas narkoba, kejujuran, kerjasama yang baik, rasa kasih sayang yang tinggi terhadap sesama, solidaritas yang tinggi, toleransi, kedisiplinan, kerajinan, prestasi olahraga, kesenian, dan kepramukaan.

Karakteristik MBS juga bisa diketahui antara lain dari bagaimana sekolah dapat mengoptimalkan kinerja organisasi sekolah, proses belajar-mengajar, pengelolaan sumber daya manusia, dan pengelolaan sumber daya dan administrasi. Lebih lanjut BPPN dan Bank Dunia (1999), mengutip dari Focus on School: The Future Organisation of Education Services for Student, Departement of Education, Australia 1990, mengemukakan ciri-ciri MBS dalam bagan berikut: ${ }^{6}$

Dengan demikian, Sagala dalam bukunya Manajemen Strategik dalam Peningkatan Mutu Pendidikan secara umum memaparkan karakteristik MBS antara lain: ${ }^{7}$

1. Memiliki output, yaitu prestasi pembelajaran dan manajemen sekolah yang efektif.

2. Efektifitas proses belajar mengajar yang tinggi

\footnotetext{
${ }^{6}$ Mulyasa, Manajemen Berbasis Sekolah: Konsep, Strategi dan Implementasi, (Cet. XI; Bandung: PT Remaja Rosdakarya, 2007), h. 29.

${ }^{7}$ Syaiful Sagala, Manajemen Strategik dalam PEningkatan Mutu Pendidikan, (Bandung: PT Alfabeta, 2010), h. 161.
} 
3. Peran kepala sekolah yang kuat dalam mengkoordinasikan, menggerakkan, dan menyerasikan semua sumber daya pendidikan yang tersedia.

4. Lingkungan dan iklim belajar yang aman, tertib, dan nyaman sehingga manajemen sekolah lebih efektif.

5. Melakukan analisa kebutuhan, perencanaan, pengembangan, evaluasi kerja,, hubungan kerja, dan imbalan jasa tenaga kependidikan dan guru yang dapat memenuhi kebutuhan nafkah hidupnya sehingga mampu menjalankan tugasnya dengan baik.

6. Pertanggungjawaban sekolah terhdap keberhasilan program yang telah dilaksanakan.

7. Pengelolaan dan penggunaan anggaran yang sepantasnya dilakukan oleh sekolah sesuai kebutuhan riil untuk meningkatkan mutu layanan belajar.

\section{PENUTUP}

Menurut Depdiknas, karakteristik yang harus dimiliki oleh sekolah sebagai indicator pelaksanaan MBS yang berhasil adalah sebagai berikut:

1. Input Pendidikan

a. Memiliki kebijakan mutu

b. Sumber daya tersedia dan siap

c. Memiliki harapan dan prestasi yang tinggi

2. Proses

a. Efektifitas proses belajar mengajar tinggi

b. Kepemimpinan sekolah kuat

c. Pengelolaan yang efektif tenaga kependidikan

d. Sekolah memiliki budaya mutu

e. Sekolah memiliki "teamwork" yang kompak, cerdas dan dinamis

f. Sekolah memiliki kewenangan

g. Partisipasi warga sekolah dan masyarakat

h. Sekolah memiliki keterbukaan (transparansi) manajemen

i. Sekolah memiliki kemauan untuk berubah (psikologi dan fisik)

j. Sekolah melakukan evaluasi dan perbaikan dan berkelanjutan

k. Sekolah responsive dan antisipatif terhadap kebutuhan

1. Sekolah memiliki akuntabilitas

m. Sekolah memiliki sustainabilitas

\section{Output}

Output dapat diklasifikasikan menjadi dua, yaitu output berupa prestasi akademik (academic achievement) dan output yang berupa prestasi non akademik (nonacademic achievement). 


\section{DAFTAR PUSTAKA}

Aedi, Nur, Dasar-Dasar Manajemen Pendidikan, Cet. II; Yogyakarta: Gosyen Publishing, 2015.

Engkoswara dan Aan Komariah, Administrasi Pendidikan, Cet. II; Bandung: Alfabeta, 2011.

Jalal, Fasli dan Dedi Supriadi, Reformasi Pendidikan dalam Konteks Otonomi Daerah, Yogyakarta: Adicita Karya Nusa, 2001.

Mulyasa, Manajemen Berbasis Sekolah: Konsep, Strategi dan Implementasi, Cet. XI; Bandung: PT Remaja Rosdakarya, 2007.

Nurkolis, Manajemen Berbasis Sekolah: Teori, Model dan Aplikasi, Jakarta: PT Grasindo, 2003.

Sagala, Syaiful, Manajemen Strategik dalam PEningkatan Mutu Pendidikan, Bandung: PT Alfabeta, 2010.

Usman, Husaini, Manajemen: Teori Praktik dan Riset Pendidikan, Edisi Kedua; Jakarta: Bumi Aksara, 2008.

Zahidi, Syukron, Karakteristik Manajemen Berbasis Sekolah, diakses dari file:///E:/KARAKTERISTIK\%20MANAJEMEN\%20BERBASIS\%20SEKOLAH \%20 \%20Perpus\%20Kecilku.htm, pada tanggal 22 Maret 2017 pukul 14.28 WITA. 